\title{
Educação Física e Gênero: Participação Feminina nas Atividades de Educação Física em Curso Técnico Integrado ao Ensino Médio
}

\section{Physical Education and Gender: Female Participation in Physical Education Activities in a Technical Course Integrated to High School}

\author{
Cristina Ferreira de Sá*a; Lúcio Ângelo Vidala
}

aInstituto Federal de Mato Grosso, Programa de Pós-Graduação Stricto Sensu em Educação Física. MT, Brasil.

*E-mail: cristinafnobrega@gmail.com

\begin{abstract}
Resumo
O estudo tem por objetivo buscar a reflexão sobre as relações de gênero na prática da Educação Física escolar, especificamente, nos Cursos Técnicos Integrados do Instituto Federal de Mato Grosso. Nesse sentido, a proposta é analisar detalhadamente as alunas, buscando compreender suas escolhas e preferências de modalidades esportivas para a execução das atividades nas aulas de Educação Física, tentando compreender se tais escolhas sofrem influências por serem do sexo feminino ou não. Além disso, tem-se como objetivo geral verificar diferenças entre os papéis masculinos e femininos, nas aulas de Educação Física, por meio de levantamento de dados, compreendendo assim as relações entre gênero no papel da Edu cação Física escolar. Tal estudo se remete por meio de natureza aplicada, com abordagens qualitativas e quantitativas, buscando explorar e descrever o objeto estudado de forma sistematizada e contextualizada de forma clara e didática. Espera-se que a presente pesquisa, por meio de sua proposta, possa possibilitar/ajudar uma maior interação na comunidade escolar, estimulando uma mudança na forma de agir e pensar sobre como ocorrem as relações de gênero dentro do ambiente escolar e, principalmente, nas atividades desenvolvidas pela disciplina de Educação Física escolar, contribuindo assim para uma devida formação humana democrática e integradora.
\end{abstract}

Palavras-chave: Gênero. Educação Física. Esporte. Ensino Médio.

\begin{abstract}
The objective of the study is to seek reflection on gender relations in the physical education practice at school, specifically in the integrated technical courses of the Federal Institute of Mato Grosso. In this sense, the proposal is to analyze the students in detail, seeking to understand their choices and preferences of sports modalities for the performance of activities in Physical Education classes, trying to understand whether such choices are influenced by being female or not. In addition, the general objective is to verify differences between male and female roles in Physical Education classes, through data collection, thus understanding the relations between gender roles in Physical Education school. Such a study refers through an applied nature, with qualitative and quantitative approaches, seeking to explore and describe the object studied in a systematic and contextualized way in a clear and didactic way. It is hoped that this research, throug $h$ its proposal, can enable / help greater interaction in the school community, stimulating a change in the way of acting and thinking about how gender relations occur within the school environment, and especially in activities developed by the Physical Education subject at school, thus contributing to a proper democratic and integrative human formation.
\end{abstract}

Keywords: Gender. PE. Sport. High School.

\section{Introdução}

Vive-se em uma sociedade, que mesmo diante de inúmeros avanços, apresenta alguns paradigmas patriarcais ainda presentes intensamente, podendo ser observados diariamente, e muitas vezes se acaba por partilhar e compartilhar desses valores e pensamentos, colocando o ser homem como o centro de tudo. Tal visão androcêntrica não é partilhada somente pelos homens, mas também por muitas mulheres, em consequência de possíveis influências herdadas no decorrer de sua vida. Para o patriarcalismo, o homem exerce um papel de "dominação", ou seja, consequentemente, tal visão coloca a mulher como ser inferior ao ser masculino. Essa relação de poder tem origem no processo de construção da sociedade e, assim, as mulheres recebem a todo o momento estímulos que reforçam tal concepção.
No ambiente escolar, por exemplo, as meninas diariamente recebem esses estímulos, motivo pelo qual a escola tem papel de segregar ou reforçar o sexismo, nos momentos em que essas são estimuladas a agirem de forma diferente dos meninos (MORENO, 2003).

Para Bourdieu (2009), a escola é reprodutora das desigualdades existentes na sociedade, sendo uma disputa desigual, já que é determinada pelos indivíduos. Louro (2004) defende, em seu livro, que a escola não só é formadora dessas diferenças e desigualdades como também as reproduz.

Dessa forma, o objetivo geral do presente trabalho é verificar a participação feminina nas aulas de Educação Física do Instituto Federal de Mato Grosso, especificamente, no Campus Cuiabá Octayde Jorge da Silva, ensejando situações que demonstrem se as meninas sofrem qualquer influência de 
educação patriarcal no momento de desenvolver suas escolhas nas práticas esportivas. Assim, alguns objetivos são elencados, como entender as relações de gêneros e sua construção dentro do ambiente escolar escolhido, como também compreender tais diferenças entre gênero masculino e feminino, buscando respostas sobre as influências nas aulas de prática de Educação Física escolar.

Com isso, o presente estudo pretende ajudar e compreender a complexidade das relações de gênero, no ambiente da escola, problematizando suas práticas existentes, como também proporcionar reflexões das visões e das atitudes dos professores, buscando combater discriminações e preconceitos, que possam existir no ambiente escolar.

\section{Material e Métodos}

A pesquisa foi realizada no Instituto Federal de Educação, Ciência e Tecnologia de Mato Grosso, Campus Cuiabá, e contou com a participação de 30 alunas dos $1^{\circ}, 2^{\circ}$ e $3^{\circ}$ anos, dos cursos de Secretariado, Eventos, Agrimensura e Eletroeletrônica. As alunas foram selecionadas para participarem da pesquisa de forma aleatória. A aplicação do questionário foi realizada pela pesquisadora, e o instrumento para a coleta de dados foi validado a partir de testes piloto com alunas do mesmo nível de ensino. Em razão da Pandemia da COVID-19, o instrumento utilizado para a aplicação do questionário foi o e-mail. Através do e-mail, as alunas receberam, além do questionário, os termos de consentimento (TALE e TCLE). A pesquisa foi aprovada no Comitê de Ética. A questão norteadora do presente artigo foi "a participação feminina nas atividades de Educação Física em curso técnico integrado". Os dados foram coletados entre fevereiro e outubro de 2020. Importante dizer que os dados que foram obtidos nesta pesquisa são fruto de uma dissertação de mestrado em andamento e foram interpretados utilizando-se das técnicas de análise de conteúdo de Bardin (2016), e discutidos com base nos referenciais teóricos de gênero e estudos sobre a participação feminina nas aulas práticas de Educação Física.

\section{Resultados e Discussão}

Utilizando os passos metodológicos, os dados foram extraídos na análise, que são fruto de uma dissertação de mestrado em andamento. Nesta dissertação ocorreram várias etapas, para que se chegasse aos dados obtidos, que confirmem ou não a proposta da pesquisa. Essas etapas foram organizadas em três fases, sendo a primeira a préanálise, a segunda exploração do material e a terceira o tratamento dos resultados, inferência e interpretação. Conforme o Quadro 1, em que se demonstra o roteiro da coleta dos dados para análise do conteúdo.

Quadro 1 - Roteiro didático

\begin{tabular}{|c|c|c|}
\hline Etapas & Intenções & Ações \\
\hline $\begin{array}{l}1^{\circ} \text { Etapa: Pré- } \\
\text { análise }\end{array}$ & $\begin{array}{l}\text { - Leitura flutuante; } \\
\text { - Escolha dos documentos; } \\
\text { - Formulação das hipóteses e objetivos; } \\
\text { - Elaboração de indicadores; }\end{array}$ & $\begin{array}{l}\text { - Primeiro contato com os documentos coletados. - Definição } \\
\text { do corpus para análise (obedecendo às seguintes regras: } \\
\text { exaustividade; representatividade; homogeneidade; pertinência).- } \\
\text { Leitura inicial dos dados. } \\
\text { - Interpretar o material coletado. }\end{array}$ \\
\hline $\begin{array}{l}2^{\circ} \text { Etapa: } \\
\text { Exploração do } \\
\text { material }\end{array}$ & \begin{tabular}{|l} 
- Construções das operações de codificação- \\
recortes do texto e categorização; \\
- Preparação e exploração do material- \\
alinhamento;
\end{tabular} & $\begin{array}{l}\text { - Desmembramento do texto em unidades/ categorias- isolamento } \\
\text { dos elementos; } \\
\text { - Reagrupamento por categorias para análise posterior } \\
\text { classificação (organizar a partir dos elementos repartidos). }\end{array}$ \\
\hline $\begin{array}{l}3^{\circ} \text { Etapa: } \\
\text { Tr a t a m e n t o } \\
\text { dos dados e } \\
\text { interpretação }\end{array}$ & $\begin{array}{l}\text { - Interpretação dos dados brutos (falantes); } \\
\text { - Síntese e seleção dos resultados (informações } \\
\text { fornecidas pelas análises). }\end{array}$ & $\begin{array}{l}\text { - Inferências e interpretação com abordagem variante/qualitativa, } \\
\text { com significações em lugar de inferências estatísticas. }\end{array}$ \\
\hline
\end{tabular}

Fonte: Souza et al. (2010).

A partir dos dados obtidos, nos questionários, foram criadas três categorias de análise: i) percepção das alunas sobre as aulas de Educação Física; ii) sentimento de exclusão e desigualdade durante as aulas; iii) influência do professor e da família nas escolhas esportivas das alunas. As categorias ajudaram na compreensão e no entendimento das relações sociais, e quais fatores influenciam a participação das meninas nas aulas de Educação Física Escolar do IFMTCampus Cuiabá.

Ao serem questionadas sobre qual o grau de importância das aulas de Educação Física para elas, 46,7\% responderam que era muito importante, $40 \%$ responderam que era importante e $13 \%$ responderam que tinha pouca ou nenhuma importância para elas terem aulas de Educação Física. A grande maioria das entrevistadas prefere o formato de aulas mistas, 97\%, (Figura 1 ).

Figura 1 - Importância das aulas de Educação Física para as alunas entrevistadas.

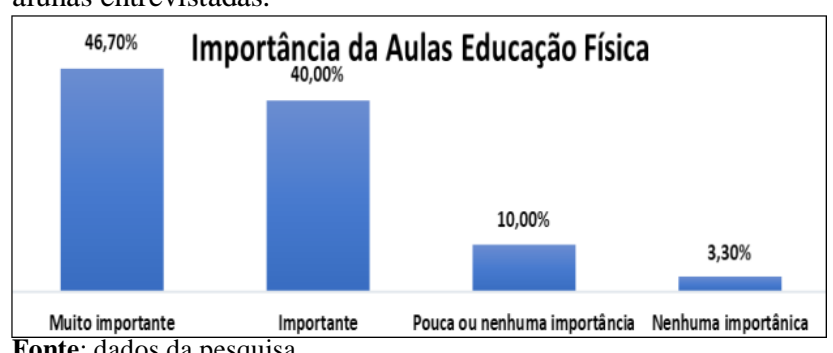

Fonte: dados da pesquisa. 
Sobre a frequência de participação nas aulas, 63,3\% responderam que participavam sempre, $23,3 \%$ participavam às vezes e as alunas que nunca participavam correspondem a $3,4 \%$. Fragmentos das repostas de algumas alunas ajudam a compreender os motivos para que elas não participassem das aulas: "Além de não gostar de esporte, não sou boa em nenhum", "não sei jogar nada mesmo", "não tenho interesse", "sou ruim, não sei jogar nada", (Figura 2).

Figura 2 - Frequência de participação das alunas entrevistadas nas aulas práticas de Educação Física

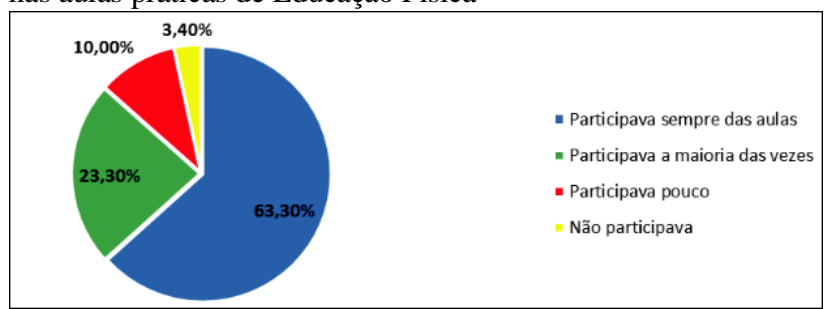

Fonte: Dados da pesquisa.

Pode-se notar indícios do esporte como principal conteúdo das aulas citadas pelas alunas, bem como o sentimento de negação das meninas em relação as suas habilidades motoras. Algumas meninas não se sentem seguras com suas habilidades corporais, o que pode limitar a participação nas atividades esportivas e o uso dos espaços físicos ocupados por elas (ALTMANN, 2015).

Ainda, de acordo com a autora, a menor habilidade motora apresentada pelas meninas em relação aos meninos, é resultado do menor tempo dedicado pelas meninas às experiências motoras. As modalidades esportivas mais praticadas por elas são: futsal, voleibol e handebol, embora, dizem apresentar dificuldades para a prática do futsal, em razão da resistência dos meninos em aceitá-las no time deles. Além disso, "os meninos acabam por considerar que as meninas não possuem a habilidade esportiva necessária ou simplesmente as excluem por serem mulheres" (MONTEIRO, 2017, p.341).

Conforme o gráfico da Figura 3 foi perguntado se as alunas se sentiam excluídas e com que frequência ocorria essa exclusão, as respostas apontaram para uma contradição, pois para a primeira pergunta, $69 \%$ das alunas responderam que não se sentiam excluídas, mas quando perguntadas sobre com que frequência ocorria a exclusão, 63,4\% relataram que quase sempre.

Figura 3 - Sentimento de exclusão e desigualdades demostrado pelas alunas entrevistadas

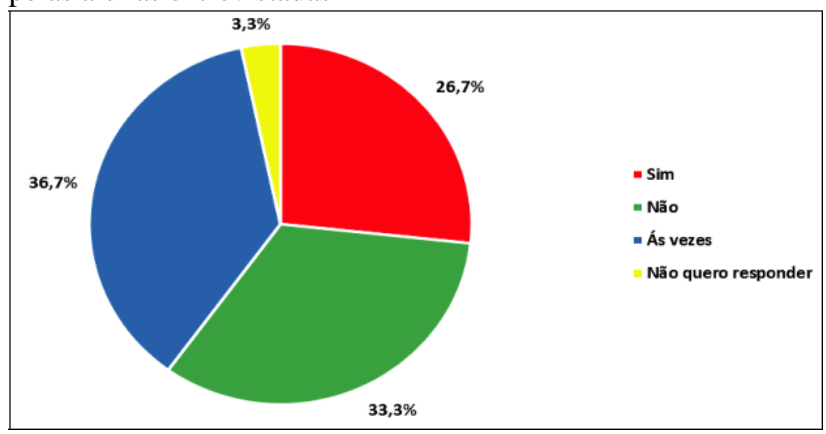

Fonte: dados da pesquisa.

Perante os dados levantados, é possível notar ainda um sentimento de preconceito contra a mulher no âmbito da Educação Física. Ocorre que, em um estudo realizado por DAROSA et al. (2012), esse demonstra que o preconceito vai além da atividade de Educação Física, estando assiduamente entrelaçado com questões culturais, familiares, educacionais, entre outros.

Nessa linha, muitos autores afirmam que é através da transmissão cultural de estereótipos que meninos e meninas ficam a mercê de experiências distintas, levando assim a exclusão e desmotivação das alunas nas atividades de Educação Física (PACE JÚNIOR et al., 2010).

Foucault (2011) explica que as relações de poder, muitas vezes, ocorrem sem a consciência do dominado. É o que se pode chamar de poder simbólico, que de acordo com Bourdieu (1989), é o poder que ocorre de forma silenciosa, invisível, em que nem mesmo o dominante e o dominado conseguem entender a relação de disputa entre esses.

No início da década de 1960 do século XX, é perceptível que algumas concepções sobre gênero começam a tomar forma através de movimentos denominados feministas, preocupados com situações sociais e políticas (LOURO, 2003). Com esses movimentos, as lutas das mulheres para obterem direitos foram se fortificando, possibilitando assim um começo na produção de uma identidade feminina. A partir disso, "elas" se organizaram e protestaram contra as diferenças "contratuais", como casamentos arranjados e sobre aquisição de direitos sobre propriedades (HALL, 2006).

De acordo com Louro (1997), tal surgimento desses movimentos no Brasil ocorreu na década de 1980 do século passado, em que o termo gênero passou a ser utilizado aos poucos nos estudos. Entretanto, o conceito de gênero, este definido como uma categoria analítica e relacional, que se articula com outra categoria, foi construída por Scott (1995).

Com os avanços da categoria, as reinvindicações da classe feminina passaram a ser mais amplas, como direito à sexualidade, e ter as mesmas oportunidades que os homens no mercado de trabalho. Daí surge o que é chamado por Louro (1997) de "terceira onda", sendo um momento de intensa reflexão e discussões em torno de raça, de sexualidade, de classe social e de gênero. Com o surgimento dessa categoria, passou a ocorrer um divisor de águas, em que a concretização do conceito de gênero deu ênfase ao caráter social do "ser mulher", se não apenas meras diferenças biológicas de sexo.

Por outro lado, avançando no tempo, a relação diretamente de gênero e Educação Física no Brasil surgiu em meados da década de 1980, com questões que abrangiam classe social, religião, raça e identidade, substantivos denominados como polêmicos. A partir disto, o estudo de gênero na Educação Física passou a ser apresentado como uma categoria analítica, devidamente definida por construções históricas culturais, como masculino e feminino (DEVIDE, 2017). 
Com isso, surgiram pesquisas envolvendo gênero na Educação Física, isso por volta da década de 1990. A autora cita a tese de doutorado de Eustáquia Salvadora de Souza, como a primeira pesquisa a abordar, especificamente, sobre gênero e Educação Física, o tema da referida tese de doutorado era "Meninos, à marcha! Meninas, à sombra!" A história da Educação Física em Belo Horizonte 1897-1994 (ALTMANN, 2015).

Entretanto, o fim da separação entre meninos e meninas nas aulas de Educação Física escolar somente surgiu a partir da década de 1990 do século XX, motivando inúmeros estudos e pesquisas sobre gênero na Educação Física escolar, principalmente, nas redes públicas de ensino. Partindo deste contexto, surgiram as aulas mistas e seus impactos de ensino e aprendizagem começam a surgir como categoria de pesquisa de gênero (DEVIDE et al, 2011).

Louro (2001) ainda indica que um ambiente escolar reflete nas relações de gênero, mencionando como a aula de Educação Física escolar tem influência por meio das atividades corporais a elaboração da masculinidade e feminilidade, veja-se:

Se em algumas áreas escolares a constituição da identidade de gênero parece, muitas vezes, feita através dos discursos implícitos, nas aulas de EF esse processo é, geralmente mais explícito e evidente (LOURO, 2001, p.72).

Para Bourdieu (2014), as diferenças construídas socialmente acabam legitimando as relações de denominação, e a partir disso, as escolas têm se constituído em um local reforçado dessas desigualdades. Por outro lado, o autor afirma ainda que o habitus primário é adquirido no seio familiar, no qual a família transfere às crianças o seu capital cultural, passando a interferir incisivamente em suas escolhas e vivências escolares. O sistema de ensino também passa a formar e inculcar um habitus secundário sobre o habitus primário, não o substituindo totalmente, mas reforçando e reproduzindo suas condições sociais, criando novas estruturas objetivas duráveis.

Inúmeros estudiosos observam em suas pesquisas significativas diferenças entre homens e mulheres durante a atividade física nas escolas. Na visão de Souza (2009), nas aulas de Educação Física de Ensino Fundamental, meninos buscam maiores atenções e se investe na prática dos desempenhos das atividades que foram propostas, enquanto as meninas se limitam a preocupações estéticas, com aparência física. Naturalmente, essas diferenças são notadas e ocorrem de forma sistemática, normalmente se manifestando nos períodos de preparações para o início das aulas de Educação Física escolar. Existem instituições que desempenhavam as atividades, de forma separada, como escolas de especialização em diferentes modalidades esportivas, as atividades passaram a ser realizadas de forma conjunta, tendo em vista a pouca procura por parte das meninas, situação que obriga, indiretamente, a intervenção do docente nas relações de gênero em um espaço educativo (ALTMANN, 2015).

Garret (2004) afirma que a aula de Educação Física perde a sua função pedagógica de garantir o acesso ao conhecimento específico da área, tornando-se um espaço de demonstração de habilidades, um espaço apenas de aprendizagem de educação corporal, de gesto e de movimento.

Um particular desafio para a educação física é encontrar maneiras de empoderar meninas e jovens mulheres a sentirem-se mais confiantes e habilidosas ao usarem seus corpos em vez de constrangidas por formas restritivas de padrões corporais de gênero (GARRET, 2004 p. 235).

Percebe-se que a mensagem passada é que a conquista do espaço nos esportes pelas mulheres ocorreu por meio de suas habilidades e não pela beleza. $\mathrm{O}$ que ao final das contas se sobressai é um corpo forte, hábil, resistente, ou seja, um corpo de atleta (ALTMANN, 2015).

\section{Conclusão}

O estudo possibilitou analisar como as alunas do Instituto Federal de Mato Grosso (IFMT), Campus do município de Cuiabá, buscam escolher atividades esportivas oferecidas durante aulas de Educação Física. Ficou demonstrado que suas escolhas carregam influências da sociedade patriarcal, como também, que as relações de gêneros presentes nas atividades desempenhadas, em aulas de Educação Física, remetem a formas de discriminações, sendo necessário compreender o papel da Educação Física na reprodução de estereótipos e preconceitos.

Foi possível verificar que as meninas sofrem influências da sociedade sexista na hora de praticar determinadas modalidades esportivas, culturalmente, dominadas por homens. Com isso, no IFMT, as aulas de Educação Física, apesar do grande avanço, ainda refletem as diferenças entre as oportunidades que são disponibilizadas para meninas e meninos, ou seja, pode-se dizer que a Educação Física ainda continua sendo um espaço de atividade física que favorece o desenvolvimento motor e social dos meninos, tornando-se assim uma expressão de masculinidade hegemônica.

As meninas, muitas vezes, são excluídas dessas atividades, entretanto, muitas ainda se autoexcluem, inclusive, de simples atividades corporais, por acharem não estar adequada aos padrões corporais exigidos. Nesse ponto, o ambiente familiar tem papel indispensável na influência de possíveis definições culturais, ou seja, o que deve ser de menino ou de menina, em que essas definições podem ser ensinadas e reproduzidas, evitando assim autobloqueio psicológico/cultural de meninas na prática de esportes.

Além disso, existem as desigualdades das habilidades corporais de meninas em relação aos meninos. Estudos afirmam que grande parte das discriminações ocorrem por conta da suposta falta de habilidade do sexo feminino no desempenho de certos esportes, e não necessariamente somente pela questão de gênero, tanto que apontam, inclusive, que em certos esportes, os meninos também não se enquadram, por questões de padrões exigidos, sendo muitas vezes excluídos. Ocorre que este ponto é necessariamente equivocado, pois a falta ou 
deficiência de habilidades podem ser sanadas com práticas e treinos, ou seja, trata-se da desigualdade de oportunidades, que historicamente não são ofertadas às meninas.

No presente estudo, os dados obtidos permitem afirmar que as meninas, do grupo estudado, sofrem influências relacionadas ao gênero em práticas de atividade físicas nas aulas, e que essa influência esta diretamente ligada aos costumes culturais sexistas, que determinam os comportamentos supostamente adequados às meninas e aos meninos.

Percebe-se a necessidade de se questionar o sistema de dominação, por meio de elementos, que produzam uma contracultura, capaz de colocar em xeque os valores hegemônicos que se tornaram paradigmas, só assim se pode construir uma sociedade realmente igualitária em gênero. $\mathrm{O}$ presente artigo se mostra relevante nas práticas pedagógicas em busca pela inclusão e participação efetiva das meninas nas atividades desempenhadas nas aulas de Educação Física Escolar.

\section{Referências}

ALTMANN, H. A Educação Escolar: relações de gênero em jogo. São Paulo: Cortez, 2015.

BOURDIEU, P. A reprodução: elementos para uma teoria do sistema de ensino. Petrópolis: Vozes, 2014.

BORDIEU, P. A dominação masculina. Rio de Janeiro: Bertrand Brasil, 2002.

DAROSA, M.V.; DE OLIVEIRA SOUZA, M.; BORGES, A.M. Preconceito contra a mulher na educação física escolar no nono ano. Rev. Prâksis, v.1, p.102-117, 2020.
DUARTE, C.S.B. Democracia, desigualdade e desenvolvimento em perspectiva comparada. Brasília: UnB, 2009.

DEVIDE, F.P. Estudos de gênero na educação física e no esporte. Curitiba: Appris, 2017.

FOUCAULT, M. Vigiar e punir: nascimento da prisão. Petrópolis: Vozes, 2011.

GARRETT, R. Negotiating a physical identity: girls, bodies and Physical Education. Sport, Educ. Soc., v.9, n.2, p.223-237, 2004.

HALL, S. A identidade cultural na pós-modernidade. Rio de Janeiro: DP\&A, 2006.

LOURO, G.L. Nas redes do conceito de gênero. In: LOPES, M. et al. (Org.). Gênero e saúde. Porto Alegre: artes Médicas, 1996. p. 7-18.

LOURO, G.L. A construção escolar das diferenças. In: LOURO, G. Gênero, sexualidade e educação: uma perspectiva pósestruturalista. Petrópolis; Vozes, 2010. p.57-87.

LOURO, G.L. A emergência do gênero. In: LOURO, G. Gênero, sexualidade e educação: uma perspectiva pós-estruturalista. Petrópolis: Vozes, 2010. p.14-37.

MONTEIRO, M.V.P. A construção identitária nas aulas de Educação Física. Rev. Bras. Educ., v.22, n.69, p.339-359, 2017.

MORENO, M. Como se ensina a ser menina: o sexismo na escola. São Paulo: Moderna, 2003.

PACE JÚNIOR, R.L. et al. Gênero e Educação Física Escolar. Rev. Digital, n.147, 2010. Disponível em: https://www.efdeportes. com/efd147/genero-e-educacao-fisica-escolar.htm

SCOTT, J. Gênero: uma categoria útil de análise histórica. Educ. Realidade, v. 20, n. 2, 1995.

SOUZA, C.M. Relações de gênero e Educação Física: visão de jogo e beleza. Campinas: Unicamp, 2009. 